\title{
Barras de FRP: Avaliando o Módulo de Elasticidade não Destrutivamente
}

\author{
Protasio F. Castro
}

Resumo: Um estudo experimental foi realizado com o objetivo de contribuir com o desenvolvimento de métodos de ensaios de avaliação das características mecânicas das barras de plástico reforçado com fibra (FRP) a serem utilizadas como armadura nas obras de engenharia civil. Comparou-se o módulo de elasticidade estático, obtido por ensaio de tração em uma máquina universal, com o módulo de elasticidade dinâmico, obtido por ensaios não destrutivos. O módulo de elasticidade dinâmico foi determinado utilizando-se dois métodos de propagação de ondas: o pulso ultra-sônico e a frequiência de ressonância. Os valores do módulo de elasticidade dinâmico e os valores do módulo de elasticidade estático obtidos a partir da curva tensãodeformação dos ensaios de tração são significativamente semelhantes. Os resultados mostram que os ensaios de módulo de elasticidade dinâmico possuem potencial para serem utilizados na linha de fabricação das barras de FRP como controle da produção.

Palavras-chave: Plástico reforçado com fibra, módulo de elasticidade, ensaio não destrutivo, barras de armação, freqüência de ressonância, pulso ultra-sônico.

\section{Introdução}

Compósitos pultrudados ${ }^{(\mathrm{NA1})}$ de plásticos reforçados com fibra (FRP) na forma de barras já estão disponíveis no mercado como uma alternativa para as barras metálicas de armação para concreto. Comparadas com o aço, as barras de FRP oferecem vantagens, tais como, massa reduzido e resistência à corrosão na presença de íons cloreto. Entretanto, sua utilização na engenharia civil terá de transpor barreiras que se iniciam pela tradição conservadora da indústria de construção e crescem nos seguintes aspectos técnicos:

- o comportamento da curva tensão-deformação à tração é muito próximo ao de um material frágil e elástico-linear; o que faz com que as atuais equações de projeto, baseadas no comportamento elástico-plástico do aço, sejam inaplicáveis. Portanto, como resultado desse tipo de comportamento, novos métodos de projeto serão necessários para garantir segurança e a vida útil para os elementos estruturais armados com barras de FRP.

- a natureza frágil das barras de FRP torna impossível o dobramento no campo. Portanto, as barras de FRP deverão ser dobradas nas plantas industriais de sua produção. Entretanto, nas grandes cidades já existem inúmeras prestadoras de serviços que colocam a barra de aço dobrada no canteiro de obra. Isso mostra que a tendência de se ter um canteiro de obra desobstruído é favorável para as barras de FRP que deverão ser dobradas na fábrica. 
- o módulo de elasticidade é menor do que o do aço, o que ocasiona maiores flechas e aberturas de fissuras nos elementos sujeitos à flexão.

- a falta de normas e métodos de ensaio dificultam a especificação de barras de FRP pelos engenheiros em seus projetos.

As barras de FRP são compósitos de fibras contínuas (em geral de vidro) embebidas em uma matriz polimérica (poliéster, viniléster, epoxi etc). A matriz serve para proteger as fibras e efetuar a transferência de cargas da superfície da barra para o interior e para as fibras. Em geral, as barras de armação em FRP são fabricadas pelo processo de pultrusão. Nesse processo, as fibras contínuas são embebidas com resina e puxadas através de um molde aquecido para produzir a forma da seção transversal desejada. Após a barra passar pelo molde, diferentes processos são usados para impor uma deformação à superfície da barra, garantindo uma maior aderência como armadura para concreto. Após o processo de moldagem e execução da superfície final da barra, deixa-se a resina polimerizar.

As propriedades mecânicas das barras são influenciadas pelas propriedades das fibras e da resina, pela fração em volume das fibras e da resina e pela eficiência em transferir as tensões da superfície da barra para o interior das fibras. A regra das misturas é freqüentemente utilizada para avaliar as propriedades mecânicas das barras de FRP, isto é, segundo Harris (1985) ${ }^{1}$ :

$$
\mathrm{P}_{f r p}=\mathrm{P}_{f} \mathrm{v}_{f}+\mathrm{P}_{m} \mathrm{v}_{m}
$$

onde:

$\mathrm{P}_{f r p}=$ propriedade mecânica da barra de FRP,

$\mathrm{P}_{f}=$ propriedade mecânica das fibras,

$\mathrm{v}_{f}=$ fração volumétrica de fibras,

$\mathrm{P}_{m}=$ propriedade mecânica da matriz,

$\mathrm{v}_{m}=$ fração volumétrica de matriz.

Entretanto, Noritake et al. (1993) $)^{2}$ notaram que, quando as barras são formadas por múltiplos feixes de fibras impregnadas de resina, a resistência à tração obtida experimentalmente é menor do que a resistência à tração teórica, isto é, prevista pela teoria.

O mercado brasileiro possui apenas um fabricante de barra de FRP, que só as produz sob encomenda direta. No mercado americano existe atualmente uma enorme variedade comercial de barras de FRP para uso como barra de armação para concreto. Todas as barras são fabricadas em diferentes dimensões, com- posições e configurações de superfície. Para facilitar a aplicação desses produtos será necessário desenvolver normas de projeto, de especificação e de métodos de ensaios. As principais propriedades mecânicas são: a resistência à tração, o módulo de elasticidade e o comprimento de ancoragem ${ }^{(\mathrm{NA} 2)}$. Outras propriedades incluem a resistência ao corte no sentido normal à superfície da barra, para o caso de uso como barra de transferência em pavimentos, e o corte no sentido paralelo ao plano das fibras ou eixo longitudinal da barra.

As barras de FRP não podem ser ensaiadas à tração utilizando-se simplesmente as mesmas técnicas usadas para as barras de aço. Se uma barra de FRP é carregada em ensaio de tração, usando-se as garras de fricção da forma tradicional, a combinação de elevadas tensões de compressão e o dano mecânico causado pela "mordida" da garra provocarão a ruptura prematura da barra, na região de aperto das garras. Há uma necessidade de desenvolvimento de um método confiável para avaliação da resistência de tração das barras. Atualmente o subcomitê D 20.18 da American Society for Testing Materials (ASTM) está analisando alguns processos para desenvolver o método de ensaio de tração para barras de FRP utilizadas como barras de armação para concreto.

Nas barras de aço o módulo de elasticidade pode ser considerado o mesmo para barras de diferentes fabricantes. Para as barras de FRP o módulo de elasticidade dependerá dos materiais utilizados, da fração em volume dos materiais e dos detalhes do processo de fabricação (obtenção da superfície acabada). Considerando-se que os fabricantes utilizam métodos de produção distintos, além de diferentes materiais componentes, será necessário medir o módulo de elasticidade das barras como produto final acabado. Tradicionalmente, o módulo de elasticidade é obtido a partir da parte linear da curva tensão-deformação extraída durante o ensaio de tração. Técnicas de colagem de medidores elétricos de deformação (strain-gages) sobre FRP necessitam ser desenvolvidas para garantir que as barras não sejam danificadas durante a colocação do "strain-gage". Isso é particularmente importante pois barras com superfícies de formas e de texturas diferentes já estão disponíveis no mercado. Extensômetros elétricos podem ser utilizados, mas precisam ser projetados de forma apropriada para atender aos diferentes tipos de barra. Uma alternativa é medir o módulo de elasticidade dinâmico usando métodos 
de propagação de ondas, tais como, o pulso ultrasônico (ASTM C 597) ${ }^{3}$ e a frequiência de ressonância (ASTM C 215)

Este trabalho é uma contribuição ao desenvolvimento da avaliação do módulo de elasticidade das barras de FRP para armação de concreto. O trabalho compara os valores do módulo de elasticidade dinâmico obtido por métodos de propagação de onda com os valores de módulo de elasticidade obtidos por ensaio de tração.

\section{Módulo de Elasticidade Dinâmico}

Os dois métodos de determinação do módulo de elasticidade dinâmico estudados para as barras de FRP foram adaptados dos ensaios não destrutivos de concreto. Eles foram o método de ensaio por pulso ultra-sônico (ASTM C 597) ${ }^{3}$ e o método da freqüência de ressonância.

No método de ensaio por pulso ultra-sônico medese o tempo de "viagem"(NA3) de um pulso ultra-sônico através do objeto ensaiado. O pulso é emitido por um transdutor piezoelétrico acoplado a um lado do objeto e recebido por um transdutor similar acoplado no lado oposto do objeto. Em geral utiliza-se vaselina ou graxa como material para acoplagem dos transdutores. Um equipamento de medição de tempo é utilizado para medir e mostrar o tempo de "viagem" do pulso, e a maioria dos equipamentos permite medi-lo com resolução de $0,1 \mu$ s. A velocidade do pulso é calculada dividindo-se a distância entre o centro dos transdutores $(L)$ pela medida do tempo de " $v i$ agem" do $\operatorname{pulso}(\Delta t)$ :

$$
\mathrm{V}_{\mathrm{p}}=\frac{L}{\Delta t}
$$

Segundo Jones (1962) ${ }^{5}$ a velocidade de propagação da onda de vibração de compressão através de um sólido elastico isotrópico está diretamente relacionada com a densidade $(\rho)$, com o módulo de elasticidade $(E)$ e com o coeficiente de Poisson $(v)$, como mostrado na Equação 3.

$$
\mathrm{V}_{\mathrm{p}}=\sqrt{\frac{E(1-\mathrm{v})}{\rho(1-2 \mathrm{v})(1+\mathrm{v})}}=\sqrt{\frac{E}{\rho} \mathrm{k}}
$$

Combinando-se as equações 2 e 3 obtem-se:

$$
E_{\text {upv }}=\frac{\rho}{k}\left(\frac{L}{\Delta t}\right)^{2}
$$

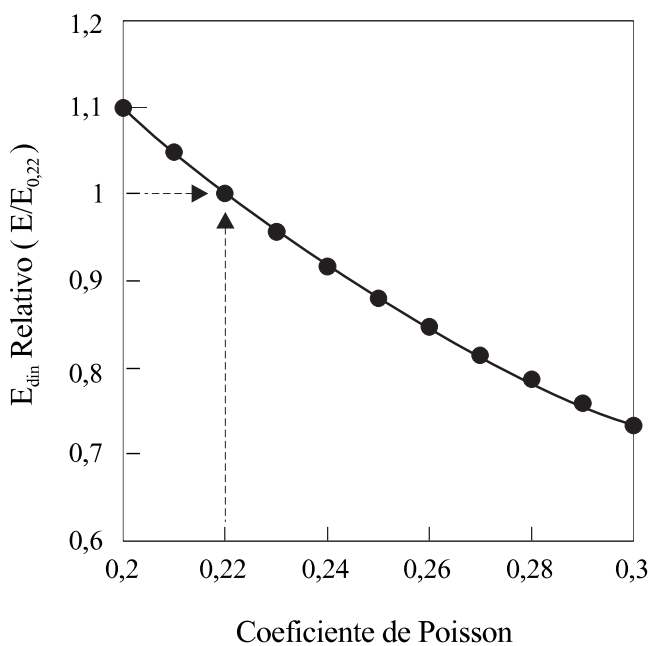

Figura 1. Variação relativa do módulo de elasticidade dinâmico em função do coeficiente de Poisson.

Logo é necessário conhecer a densidade e o coeficiente de Poisson da barra de FRP para que o módulo de elasticidade dinâmico $\left(E_{u p v}\right)$ possa ser calculado a partir do tempo de "viagem" do pulso ultra-sônico. Segundo Benmokrane et al $(1995)^{6}$ o valor do coeficiente de Poisson para fibras de vidro varia de 0,20 a 0,22 , e para matriz de resina epoxídica varia de 0,20 a 0,33. Neste trabalho adotou-se o valor de 0,22 para coeficiente de Poisson como recomendado no manual de projeto da Morrison Molded Fiber Glass Co. $(1995)^{7}$ para os produtos, barras e perfis, em compósito pultrudados. A Figura 1 mostra a variação percentual do módulo de elasticidade dinâmico, adotando-se o valor do módulo correspondente a um coeficiente de Poisson de 0,22 como 100\%.

O módulo de elasticidade dinâmico pode ser determinado a partir de medidas da frequiência de ressonância longitudinal da barra. A freqüência de ressonância longitudinal pode ser obtida fixando-se um acelerômetro a um dos extremos da barra e batendo no outro extremo com um pequeno martelo. Segundo a ASTM C $215^{4}$, esse procedimento é denominado de ressonância de impacto. A resposta do acelerômetro é anotada através de analisador digital de frequiência e a freqüência fundamental de ressonância é obtida a partir de uma análise dos componentes da freqüência no sinal do acelerômetro. Malhotra e Carino (1991) $)^{8}$ mostraram que a velocidade da onda de compressão $(V)$ na barra está relacionada com a frequiência de ressonância longitudinal $\left(f_{L}\right)$ e com o comprimento da barra $(L)$, como mostrado na Equação 5.

$$
V=2 f_{L} L
$$


Ainda segundo Malhotra e Carino, para um cilindro delgado a velocidade da onda de propagação está relacionada com o módulo de elasticidade dinâmico $E_{\text {din }} \mathrm{e}$ com a densidade $(\rho)$ como mostra a Equação 6.

$$
V=\sqrt{\frac{E_{\operatorname{din}}}{\rho}}
$$

Combinando-se as Equações 5 e 6 obtém-se a seguinte relação para cálculo do módulo de elasticidade dinâmico a partir da frequiência de ressonância longitudinal:

$$
E_{\text {din }}=4 \rho L^{2} f_{L}^{2}
$$

\section{Experimental}

A ASTM D $3916^{9}$ estabelece procedimento de ensaio de tração para barras de FRP lisas com diâmetro variando de 3,2 a 25,4 mm. Essa norma especifica um adaptador de aluminio que é colocado nas garras da máquina de ensaio. $\mathrm{O}$ adaptador tem como objetivo garantir que a "mordida" da garra não provoque a ruptura prematura da barra, na região de aperto das garras. O adaptador para garras da ASTM D $3916^{9}$ foi desenvolvido para barras lisas. Ensaios em barras com superfícies preparadas para elevada aderência barra-concreto utilizando o adaptador não apresentaram repetibilidade e reprodutibilidade de resultados significativos.

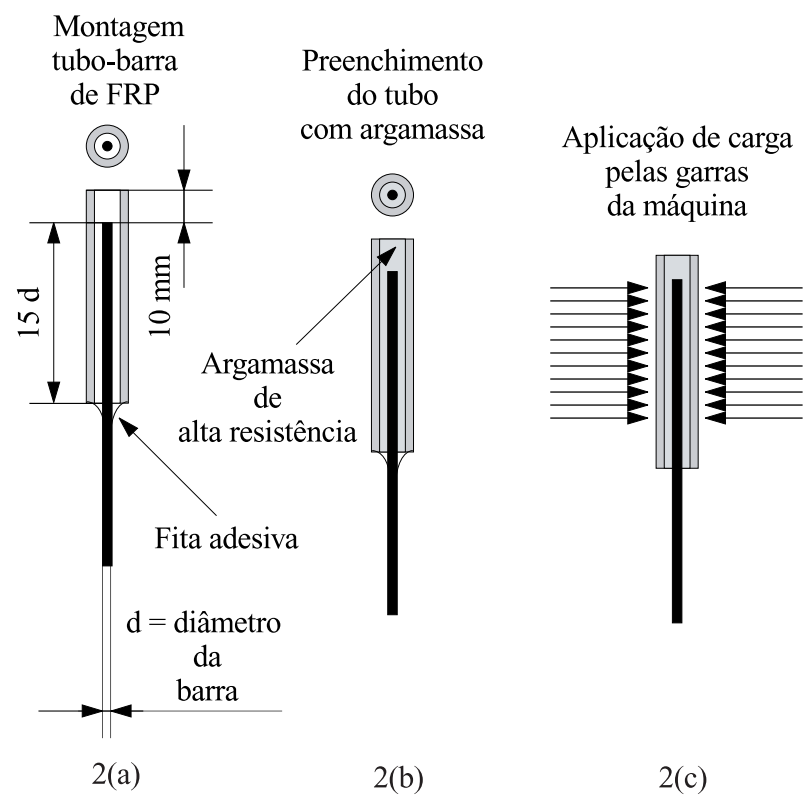

Figura 2. Sistema de carregamento no ensaio de tração das barras de FRP.
Por esta razão, o ensaio de tração foi realizado utilizando-se um sistema simples e econômico que consiste em embeber os extremos da barra de FRP em um tubo metálico e preencher o espaço entre o tubo e a barra com uma argamassa de alta resistência. $\mathrm{O}$ sistema utiliza as garras normais de uma prensa universal para ensaio de tração e está baseado na transferência da tensão de cisalhamento da argamassa para a barra de FRP. O sistema é mostrado na Figura 2.

Os ensaios de tração foram executados utilizando-se uma prensa de $270 \mathrm{kN}$ de capacidade, operada manualmente, geralmente conhecida como máquina universal de ensaios. Os corpos-de-prova ensaiados à tração foram carregados a uma taxa de $250 \mathrm{MPa} /$ minuto. Os alongamentos das barras foram medidos usando-se uma base LVDT em um extensômetro com $50,8 \mathrm{~mm}$ de base de medida. Transdutores de pressão (celula de carga) foram acoplados à máquina de tração e ao sistema hidráulico, além de LVDT fixado à mesa móvel da máquina de ensaio. O extensômetro, a célula de carga e o sensor de posicionamento da mesa móvel foram conectados a um sistema digital de aquisição de dados que fazia a leitura de três canais duas vezes por segundo. Para evitar danos o extensômetro era removido a cerca de $70 \%$ ou mais da carga de ruptura esperada para cada barra. O ensaio prosseguia até o momento da ruptura brusca do corpo-de-prova e o sistema era desligado quando ocorria uma queda da carga em mais de $10 \%$.

Apenas os resultados de ensaio em que a fratura ocorreu dentro do comprimento útil do corpo-de-prova foram considerados válidos para determinação da resistência à tração e do módulo de elasticidade da barra de FRP. Os dados eram transferidos e armazenados em um disquete e posteriormente convertidos de voltagem elétrica para unidades de engenharia através de uma curva de calibração preeviamente estabelecida. A Figura 3 mostra um exemplo típico dos dados obtidos durante a realização de um ensaio de tração em barra de FRP. A Figura 3(a) mostra a posição da mesa móvel em relação ao tempo, que pode ser utilizada para verificar a taxa de aplicação de carga no corpo-de-prova. A Figura 3(b) mostra a tensão de tração em relação a posição da mesa. Essa curva é apenas similar à curva tensão-deformação e mostra que a fratura ocorre abruptamente sem qualquer aviso do tipo alteração na inclinação da curva, como é comum em produtos de ligas metálicas. A Figura 4 mostra a curva da tensão de tração versus a deformação. A análise por regressão linear foi utili 


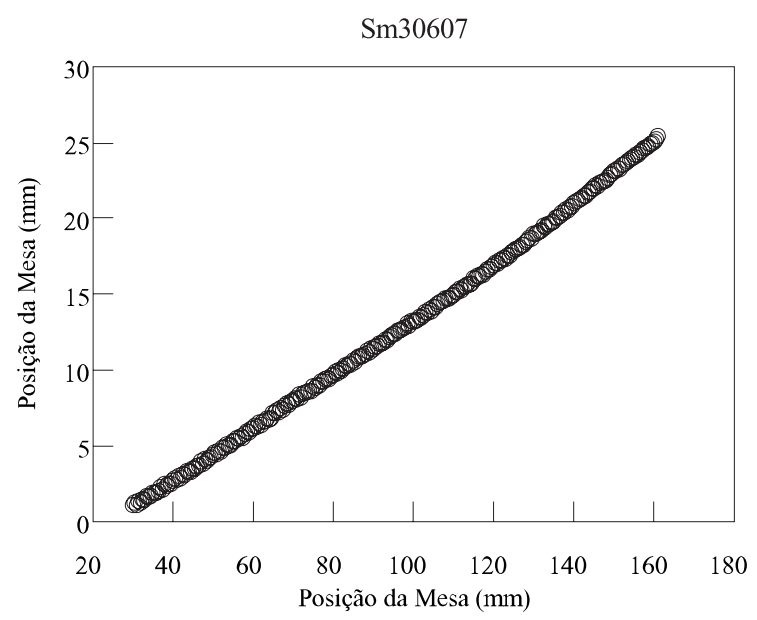

3(a) - Posição da mesa x tempo de aplicação da carga

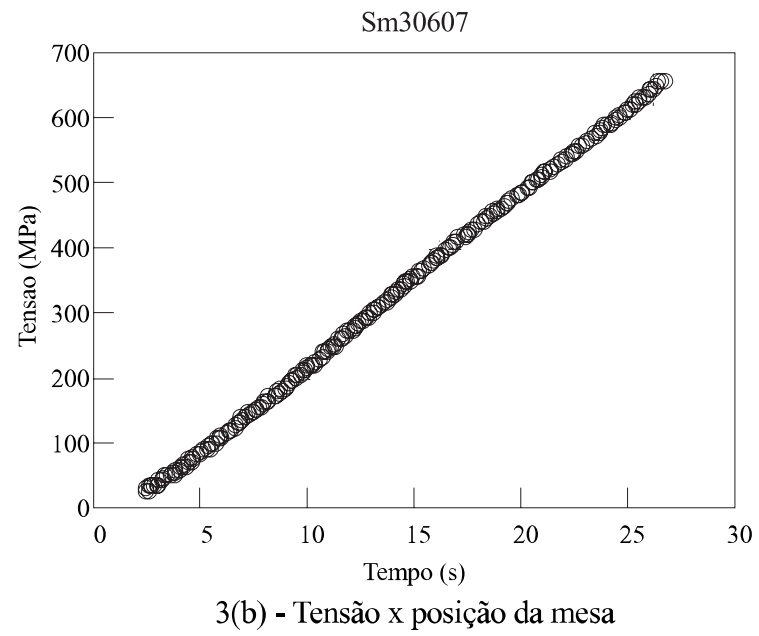

Nota:

sm - identifica barra de superficie lisa (smooth) 30607 - corpo-de-prova 3, ensaiado no mês 06 e dia 07

Figura 3. Dados típicos obtidos de ensaio de tração das barras FRP.

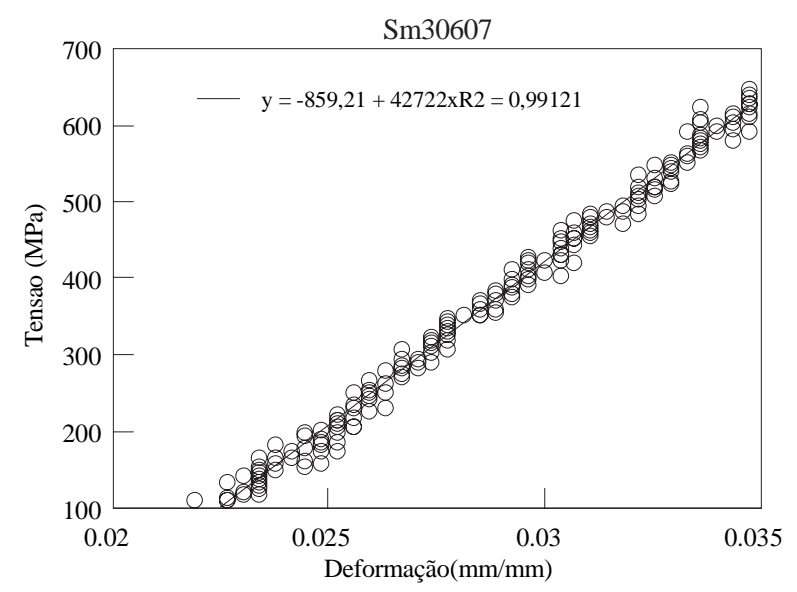

Nota:

sm - identifica barra de superficie lisa (smooth)

30607 - corpo-de-prova 3, ensaiado no mês 06 e dia 07

Figura 4. Gráfico típico do ensaio de tração para obtenção do módulo de elasticidade das barras de FRP. zada para determinar a reta que melhor se ajustava aos pontos e dessa forma avaliar o módulo de elasticidade estático.

\section{Determinação do diâmetro efetivo das barras}

Três tipos de barras de FRP para armação comercialmente disponíveis no mercado americano e dois tipos de barras de FRP lisas foram utilizadas no programa experimental desenvolvido no National Institute of Standard and Technology. Todas as barras foram fabricadas pelo processo de pultrusão e eram compostas de fibra de vidro tipo E-glass e resinas de poliéster ou viniléster. Entretanto, neste trabalho serão apresentados os resultados da série de ensaios com barras de um mesmo fabricante, a Marshall Industries Composites. Por imposição do programa experimental, a Marshall além de fornecer seu produto normal, isto é, barra com teor de fibra de $75 \%$, em volume, fabricou uma amostra com o teor de fibra de apenas 50\%. Esse apoio da Marshall ao programa experimental, possibilitou a ocorrência de variação nos valores do módulo de elasticidade das barras. Os resultados de ensaios aqui apresentados foram realizados em barra de FRP, de diâmetro nominal igual a 14,8 mm, apresentando superfície com mossas similares as das barras de aço para armação.

Para calcular a resistência à tração e o módulo de elasticidade, o diâmetro da barra deve ser conhecido. A ASTM $3916^{9}$ especifica a medida do diâmetro das barras lisas através da utilização de micrômetro em vários pontos do comprimento da barra, anotando-se o valor mínimo e a média dos valores. Esse procedimento não é adequado para as barras com superfícies propositalmente preparadas para aumentar a aderência barra-concreto devido à variação na seção transversal e à presença de mossas. $\mathrm{O}$ procedimento utilizado no programa experimental foi medir a massa, o comprimento e a densidade de uma porção representativa da barra. A densidade foi obtida pela variação de volume d'água em um picnômetro. Um projeto de análise experimental, com base na ASTM E $122^{10}$, determinou estatisticamente o comprimento adequado do corpo-de-prova para ser utilizado na determinação da densidade e o diâmetro da barra. Concluiu-se que o comprimento dos corpos-de-prova para determinação do diâmetro efetivo das barras deveria ser de $200 \mathrm{~mm}$ com quatro repetições para determinação de um valor final. $\mathrm{O}$ valor do diâmetro médio obtido para as barras fornecidas pela Marshall foi de 14,8 mm. 


\section{Determinação do módulo de elasticidade dinâmico}

O procedimento para a determinação do módulo de elasticidade dinâmico pelo método do impacto da ASTM C $215^{4}$ foi adaptado para utilização em barras de FRP. A onda de compressão foi introduzida na barra através de um golpe de martelo de aço em um dos extremos. Um pequeno martelo foi usado para introduzir um pulso com freqüência maior do que a freqüência de ressonância a ser medida. Um acelerômetro foi fixado no extremo oposto da barra através do uso de cera. $\mathrm{O}$ acelerômetro foi conectado a um analisador de espectro de onda e os dados foram gravados a uma freqüência de $20 \mathrm{kHz}$. Este valor foi estabelecido em função do comprimento do corpo-de-prova. Um analisador de espectro mostrava a amplitude do espectro do sinal do acelerômetro, a partir do qual a freqüência de ressonância era lida. A barra de FRP era apoiada em dois blocos de esponja. Os impactos eram repetidos três vezes e, na maioria dos casos, o mesmo valor digital da frequiência de ressonância era obtido ao se repetirem os impactos. Os valores médios da densidade e do diâmetro das barras, previamente determinados para cada tipo de barra, foram utilizados para calcular o módulo de elasticidade dinâmico, segundo a Equação 7. Esse módulo de elasticidade é identificado neste trabalho como $E_{\text {impact }}$.

Os ensaios de pulso ultra-sônico foram realizados nos mesmos corpos-de-prova utilizados para os ensaios de ressonância de impacto. Vaselina era passada nos transdutores de $54 \mathrm{kHz}$ e nos extremos das barras. O tempo de "viagem" do pulso foi medido com resolução de $0,1 \mu \mathrm{s}$. O módulo de elasticidade dinâmico foi calculado segundo a Equação 4, considerando-se o valor de $k=1,14$, correspondente a um coeficiente de Poisson de 0,22. Esse módulo de elasticidade é identificado neste trabalho como $E_{u p v}$.

\section{Resultados e Discussão}

O objetivo deste trabalho foi comparar os resultados de avaliação do módulo de elasticidade de barras de FRP através de dois métodos de ensaios não destrutivos e o módulo de elasticidade estático obtido da curva tensão-deformação obtida do ensaio de tração.
Tabela 1. Valores dos módulos de elasticidade obtidos pelos três métodos de ensaio.

\begin{tabular}{|c|c|c|c|c|}
\hline $\begin{array}{l}\text { Identificaç- } \\
\text { ão da barra }\end{array}$ & $\begin{array}{c}\text { Resistênci- } \\
\text { a à tração } \\
\text { (MPa) }\end{array}$ & $\begin{array}{c}\text { Módulo de } \\
\text { elasticida- } \\
\text { de pelo } \\
\text { impacto } \\
(\mathrm{GPa})\end{array}$ & $\begin{array}{l}\text { Módulo de } \\
\text { elasticida- } \\
\text { de pelo } \\
\text { UPV } \\
(\mathrm{GPa})\end{array}$ & $\begin{array}{c}\text { Módulo } \\
\text { de } \\
\text { elasticida- } \\
\text { de por } \\
\text { tração } \\
\text { (GPa) }\end{array}$ \\
\hline BCCE & 420,82 & 33,53 & 31,93 & 32,03 \\
\hline ВCCB & 464,83 & 33,09 & 32,17 & 32,44 \\
\hline BCCJ1 & 402,60 & 33,03 & 32,09 & 33,76 \\
\hline BCCI & 495,82 & 33,03 & 32,14 & 32,06 \\
\hline $\mathrm{BCBJ}$ & 420,30 & 33,09 & 32,15 & 33,00 \\
\hline $\mathrm{BCCF}$ & 450,25 & 33,28 & 31,72 & 32,69 \\
\hline BCCG & 426,29 & 33,09 & 31,62 & 32,07 \\
\hline BCCD & 619,265 & 33,39 & 32,17 & 33,09 \\
\hline $\mathrm{BCBH}$ & 469,52 & 32,98 & 32,02 & 47,54 \\
\hline BCCJ & 577,07 & 32,98 & 31,94 & 34,67 \\
\hline BBEC & 353,64 & 41,77 & 40,14 & 41,11 \\
\hline BBFA & 446,08 & 41,91 & 40,44 & 38,44 \\
\hline BBEF & 300,25 & 42,2 & 40,53 & 40,37 \\
\hline BBEH & 447,39 & 41,77 & 40,37 & 41,77 \\
\hline BBEG & 425,51 & 42,27 & 40,47 & 42,27 \\
\hline BBED & 449,73 & 42,2 & 40,21 & 38,94 \\
\hline BBFB & 469,00 & 42,2 & 40,4 & 40,82 \\
\hline
\end{tabular}

Nota: Barras ensaiadas com comprimento livre entre as garras da máquina de 50 diâmetros. Identificação:

- "BC" para a barra de seção circular e teor de fibra de aproximadamente $50 \%$

- "BB" para a barra de seção circular e teor de fibra de aproximadamente $75 \%$

- Os dois últimos dos quatro caracteres de identificação das barras foram estabelecidos pelo fabricante para caracterizar as amostras em relação a produção (início, meio e fim do rolo de fibras).

As Tabelas 1 e 2 mostram os valores dos módulos de elasticidade obtidos pelos três métodos para as barras Marshall utilizadas no programa experimental. Esses resultados e a Figura 5 mostram que:

- os valores do módulo de elasticidade $\left(E_{\text {est }}\right)$ obtidos das curvas tensão-deformação dos ensaios de tração possuem maior variação do que os valores obtidos por ensaios não destrutivos.

- os valores obtidos pelo ensaio de impacto $\left(E_{\text {impact }}\right)$ são superiores àqueles obtidos pelo pulso ultra-sônico $\left(E_{u p v}\right)$.

Uma análise estatística utilizando ANOVA e o método de Scheffé ${ }^{11}$ mostrou que não existe diferença significativa entre $E_{\text {est }}$ e $E_{u p v}$ para as diversas barras de FRP utilizadas no programa experimental. Para um nível de significância de 0,001 há uma diferença significativa entre $E_{\text {impact }}$ e $E_{\text {est }}$ e entre $E_{\text {impact }}$ e $E_{u p v}$. 
Tabela 2. Valores dos módulos de elasticidade obtidos pelos três métodos de ensaio.

\begin{tabular}{|c|c|c|c|c|}
\hline $\begin{array}{l}\text { Identificaç- } \\
\text { ão da barra }\end{array}$ & $\begin{array}{c}\text { Resistência } \\
\text { à tração } \\
(\mathrm{MPa})\end{array}$ & $\begin{array}{l}\text { Modulo de } \\
\text { elasticidade } \\
\text { pelo } \\
\text { impacto } \\
(\mathrm{GPa})\end{array}$ & $\begin{array}{l}\text { Módulo de } \\
\text { elasticidade } \\
\text { pelo UPV } \\
(\mathrm{GPa})\end{array}$ & $\begin{array}{l}\text { Módulo de } \\
\text { elasticidade } \\
\text { por tração } \\
\text { (GPa) }\end{array}$ \\
\hline BCCD & 445,04 & 33,39 & 32,17 & 33,09 \\
\hline $\mathrm{BCBH}$ & 601,29 & 32,98 & 32,02 & 47,54 \\
\hline BCCJ & 561,45 & 32,98 & 31,94 & 34,67 \\
\hline $\mathrm{BCCD}$ & 445,04 & 33,20 & 31,93 & 32,41 \\
\hline BCBI & 601,29 & 33,12 & 32,35 & 36,21 \\
\hline $\mathrm{BCCH}$ & 561,45 & 32,96 & 31,95 & 33,10 \\
\hline $\mathrm{BCBJ}$ & 619,78 & 33,04 & 31,97 & 33,30 \\
\hline $\mathrm{BCCF}$ & 546,86 & 32,79 & 32,13 & 30,41 \\
\hline BCCG & 595,56 & 32,87 & 31,62 & 32,91 \\
\hline $\mathrm{BCBH}$ & 459,37 & 33,12 & 32,35 & 32,39 \\
\hline BCCI & 557,02 & 32,95 & 32,58 & 31,62 \\
\hline BBFC & 574,21 & 42,07 & 40,83 & 40,06 \\
\hline BBEC & 497,13 & 41,67 & 40,49 & 40,64 \\
\hline BBEJ & 364,31 & 41,97 & 40,25 & 42,48 \\
\hline BBEE & 598,69 & 42,34 & 40,91 & 42,68 \\
\hline BBEH & 515,35 & 41,67 & 41,01 & 42,30 \\
\hline BBFD & 498,69 & 41,93 & 40,46 & 46,55 \\
\hline BBEG & 494,52 & 41,67 & 40,39 & 39,85 \\
\hline BBED & 498,69 & 41,55 & 40,66 & 39,91 \\
\hline BBFB & 620,30 & 42,03 & 40,85 & 59,11 \\
\hline
\end{tabular}

Nota: Barras ensaiadas com comprimento livre, entre as garras da máquina, de 24 diâmetros. Identificação:

- "BC" para a barra de seção circular e teor de fibra de aproximadamente $50 \%$

- "BB" para a barra de seção circular e teor de fibra de aproximadamente $75 \%$

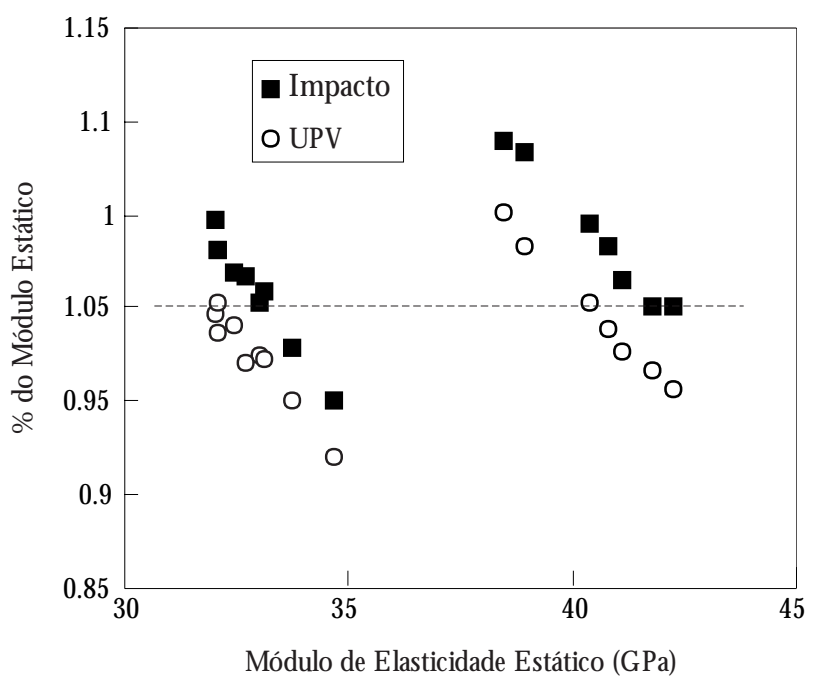

Figura 5. Variação percentual dos resultados de ensaios.
Embora exista uma conformidade entre os valores de $E_{\text {est }}$ e $E_{u p v}$ faz-se necessário notar que o valor do coeficiente de Poisson foi admitido igual a 0,22 . Isso denota a necessidade de estudos sobre o coeficiente de Poisson para barras de FRP antes que os valores do $E_{u p v}$ sejam genericamente considerados como efetivamente mais próximos dos valores de $E_{\text {est }}$.

\section{Conclusões}

Foi demonstrado que é possível utilizar os métodos de ensaios não destrutivos de propagação de onda para a avaliação do módulo de elasticidade dinâmico das barras de FRP. Os resultados mostraram uma boa conformidade entre os valores médios do módulo de elasticidade estático e os valores médios do módulos de elasticidade dinâmico.

\section{Notas do Autor}

NA1 - "Compósitos pultrudados": expressão utilizada na engenharia civil para identificar produtos em material compósito, fabricado pelo processo de pultrusão.

NA2 - "Comprimento de ancoragem": expressão utilizada na engenharia civil (estruturas) que por definição do ACI 318-95 (Building Code Requirements for Structural Concrete) é o comprimento de ancoragem necessário para as barras desenvolverem a resistência de projeto da armadura em uma seção crítica.

NA3 - "Viagem": termo apresentado pelo Dr. Nicholas Carino em Congresso Internacional e como Chairman do Comitê do ACI (American Concrete Institute) para Ensaios Não Destrutivos de forma a caracterizar e enfatizar que no método de ensaio por pulso ultra-sônico mede-se o tempo de propagação de um pulso através do concreto ensaiado.

\section{Agradecimentos}

Ao Dr. N. Carino do National Institute of Standard and Technology pelas discussões técnicas durante a realização deste trabalho. À Morrison Molded Fiber Glass Company, à Corrosion Proof Products, a Marshall Industries Composites e à International Grating, Inc. pelas amostras de seus produtos. À CAPES pelo apoio financeiro. 


\section{Referências Bibliográficas}

1. Harris, Bryan, “Engineering Composite Materials”, The Institute of Metals, p.123, (1986)

2. Noritake, K., Kakihara, R., Kumagai, S. and Mizutani, J., "Technora and Aramid FRP Rod", in Fiber-Reiforced-Plastic (FRP) Reinforcement for Concrete Structures Properties and Applications, A. Nanni, Ed. Elsevier Science Publishers, pp. 267-290. (1993)

3. ASTM C 597, "Standard Test Method for Pulse Velocity Through Concrete”, Vol. 04.02. ASTM Standards, 1996 Annual Book of ASTM Standards, ASTM, West Coshohocken, PA.

4. ASTM C 215, "Standard Test Method for Fundamental Transverse, Longitudinal, and Torsional Frequencies of Concrete Specimens”, Vol. 04.02. ASTM Standards, 1996 Annual Book of ASTM Standards, ASTM, West Coshohocken, PA.

5. Jones, R., "Non-destructives testing of concrete", Cambridge University Press, pp. 40-68, (1962).
6. Benmokrane, B., Chaallal, O. and Masmouli, R., "Glass fibre reinforced plastic (GFRP) rebars for concrete structures", Construction and Building Materials, Vol. 9, No. 6, pp. 353-364, (1995),

7. Morrison Molded Fiber Glass Co. ”Design Manual”, Bristol VA, USA, (1995).

8. Malhotra, V. M. e Carino, N. J., "CRC Handbook on Nondestructive Testing of Concrete", CRC Press, Boston, p. 343, (1991) .

9. ASTM D 3916, "Standard Test Method for Tensile Properties of Pultruded Glass-Fiber-Reinforced Plastic Rod", Vol. 08.02. ASTM Standards, 1996 Annual Book of ASTM Standards, ASTM, West Coshohocken, PA.

10. ASTM E 122, "Standard Practice for Choice of Sample Size to Estimate a Measure of Quality for a Lot or Process", Vol. 14.02. ASTM Standards, 1996 Annual Book of ASTM Standards, ASTM, West Coshohocken, PA.

11. Bajpai,A. C.; Calus, I. M. e Fairley, J. A., "Statistical Methods for Engineers and Scien-tists", John Wiley \& Sons Ltd, Chichester, p.444, (1985), 